\title{
“Eles querem é nos pôr na briga deles!”: Um estudo de caso sobre faccionalismo e estratégias entre os índios Xavante (MT)
}

Estevão Rafael Fernandes A frase que dá o título a este trabalho - “Eles querem é nos por na briga deles” - foi

(UNIR) pronunciada em um pequeno hotel na cidade mato-grossense de Barra do Garças, na noite do dia 05 de abril de 2000. Ao longo das próximas páginas o leitor será convidado a entendê-la em seu contexto (que briga seria essa, quem somos o "nós", quem são "eles" e, mais importante, se efetivamente "nós" acabamos "entrando" na "briga" "deles" - e porque)1. Neste texto exponho e analiso, brevemente, uma situação de conflito entre duas diferentes facções Xavante da Terra Indígena (TI) São Marcos, no município de Barra do Garças (MT). Neste conflito se verificou a presença de diversos atores: além das duas facções Xavante envolvidas, missionários salesianos, a estrutura local da Fundação Nacional do Índio (Funai) e a recém-chegada equipe do Programa Xavante - agravando o clima de tensão na área. Foi justamente no âmbito desse Programa, como veremos a seguir, que tomei conhecimento da situação, tendo me deslocado para a região de Barra do Garças no primeiro semestre de 2000, auge do conflito. Desse modo, esse artigo se baseia no trabalho de campo realizado em Mato Grosso entre abril e julho de 2000, e em entrevistas com alguns Xavante de São Marcos e membros da equipe do Programa Xavante - realizadas entre setembro e outubro de 2002, na sede da Funai em Brasília. Os dados que obtive nesse período se mostraram suficientes quando tratados à luz do diálogo com a literatura Jê e Xavante.

Opto, aqui, por apresentar o contexto do Programa Xavante e da organização social daqueles índios mencionando, brevemente, o faccionalismo entre outros povos Jê. Em seguida, passo para a apresentação e análise do caso em si. Adianto que um dos aspectos aos quais pretendo chamar atenção diz respeito a um ponto ainda relativamente pouco explorado no faccionalismo Jê: sua inter-relação com a cosmologia e sua importância na manutenção das relações interétnicas a partir de uma perspectiva sócio-cosmológica. Antes de prosseguirmos, uma observação cabe ser feita. Apesar da presença salesiana ter, em parte, promovido a situação aqui tratada, não me deterei nela por três motivos básicos: a) falta de dados; b) a desconfiança dos próprios Xavante em tocar no assunto; e c) o propósito deste trabalho - remeto 
Cláudia Menezes $(1985 ; 1999)$ sobre o assunto. Ou seja, não analisarei o conflito entre as facções Xavante de São Marcos em todos os seus aspectos, antes tratarei, naquele contexto, da ação xavante em relação à Funai e da maneira com que a presença do órgão foi vista pelas partes envolvidas - bem como do modo com que foram pautadas suas ações a partir desse ponto de vista.

\section{O PROJETO XAVANTE}

Pela Portaria no 047 de 03 de fevereiro de 2000, a Presidência da Funai instituía o “Programa Regional de Apoio às Comunidades Xavante do Estado de Mato Grosso", devido à "necessidade de proporcionar melhor assistência, principalmente no que concerne à educação, meio ambiente e apoio às necessidades produtivas" daqueles índios. $O$ então Presidente da Funai, Carlos Marés, nomeou um de seus assessores, Cláudio dos Santos Romero, para coordenar tal projeto. Nesse contexto, travo conhecimento com Romero e com o “Projeto Xavante/2000", como havia sido denominado o Programa acima citado. À época, eu era estagiário de Ciências Sociais no então Departamento de Identificação e Delimitação de Terras Indígenas da Funai e teria que trabalhar "na coordenação e aplicação dos questionários nas aldeias, trabalho que será feito pelos professores indígenas e 'agentes de saúde', bem como orientar os técnicos das demais áreas, que estarão fazendo o levantamento de agricultura, pecuária, meio ambiente, etc." (Instrução Técnica Executiva $n^{\circ}$ 064/PRES de 23.03.2000).

Entre março e abril, em Brasília, participamos de diversas reuniões entre a Coordenação do Projeto e lideranças Xavante. No início de abril finalmente partimos para o Mato Grosso. No entanto, naquele momento houve uma reviravolta na Funai: Carlos Marés se demitiu da Presidência do órgão após os acontecimentos na comemoração dos 500 anos de Descobrimento, quando indígenas foram reprimidos com tiros de balas de borracha e gás lacrimogêneo em Porto Seguro. Quando isto ocorreu a equipe estava em campo, dependendo de um apoio mais efetivo ao Projeto que, em meio à dança das cadeiras que se seguiu ao episódio, foi praticamente abandonado.

Além disso, havia um clima de tensão entre os Xavante, pois nas terras indígenas São Marcos e Parabubure ocorriam disputas entre diferentes facções pelo cargo de Administrador Regional. Enquanto isso, nas Administrações Regionais (AER) de Primavera do Leste e Água Boa, os administradores (não índios) negociavam mercadorias (tais como baterias de caminhões) e favores com algumas lideranças Xavante, a fim de se garantirem nos cargos. Foi nesse contexto que boa parte das observações deste trabalho foram feitas e que a frase título deste trabalho foi pronunciada por um dos coordenadores do Programa em uma reunião interna da equipe. Isso aconteceu pouco depois de sermos visitados no hotel por um pequeno grupo capitaneado pelo cacique Orestes da aldeia São Marcos (TI São Marcos) e pouco antes de sermos visitados por outro grupo, do também cacique daquela mesma aldeia, Aniceto - trataremos de ambos, desses encontros e de seus desdobramentos, adiante. 
Os índios Xavante - ou Áuwẽ, como se autodenominam - pertencem ao tronco linguístico Macro-Jê. A atual população Xavante é de aproximadamente 15.299 indivíduos (SESAI 2011), distribuídos em cerca de 200 aldeias localizadas nas terras indígenas Marãiwatsede, Pimentel Barbosa, Areões, Parabubure, São Marcos, Marechal Rondon e Sangradouro/Volta Grande.

Seus contatos com a sociedade não indígena se tornaram sistemáticos a partir de junho de 1946, quando uma frente de atração chefiada por Francisco Meirelles conseguiu o primeiro contato oficial e pacífico com um grupo às margens do rio das Mortes. Nas décadas que se seguiram ocorreu a redução e ocupação do território Xavante por fazendas e povoados, e o agravamento de uma série de epidemias que causaram a morte de centenas de índios. Os Xavante, cada vez mais pressionados, lutaram pela recuperação e manutenção de seu território, buscando reconhecimento oficial de suas terras. Ao longo das décadas de 1970 e 1980, esses índios se mantiveram na mídia, ora confrontando fazendeiros, ora ocupando a sede da Funai em Brasília. Também data desta época a tentativa de se fazer um projeto de rizicultura mecanizada entre os Xavante (1974-1984), o que degradou ainda mais seu território, aumentando também o faccionalismo e a cisão entre aldeias - eram 6 aldeias no início do projeto e uma década depois esse número já ultrapassava $50^{2}$.

Ao longo dessas lutas, os Xavante elaboraram mecanismos originais de se colocar frente ao não índio, sabendo se utilizar da visibilidade que a imprensa lhes garantia para buscar seus objetivos. Na década de 1990 a maior parte das terras Xavante foram registradas e homologadas. Os Xavante permaneceram na mídia, com a participação no CD Roots, da banda de rock Sepultura. Surgiram também uma série de eventos, especialmente na cidade de São Paulo, coordenados por organizações Xavante, a fim de divulgar a cultura daquele povo.

Tais esforços não podem ser entendidos fora do contexto das disputas por poder e prestígio, luta por direitos, busca por visibilidade e fortalecimento da liderança por meio da obtenção e distribuição dos bens obtidos junto aos não índios. Gradativamente, os Xavante foram aprendendo a usar várias formas de pressão: as ocupações na sede da Funai em Brasília por meio de ações performáticas, as "tomadas de viaturas", o uso de gravadores etc. É característica dos Xavante sua veia política, sua imaginação e originalidade na luta pelo que buscam. Tais demonstrações estão estreitamente ligadas a alguns aspectos de sua estrutura política e organização social.

Nesse sentido, Maybury-Lewis (1984) distingue dois tipos de comunidades Xavante. O primeiro seria constituído pelos Xavante Ocidentais, habitantes das regiões do alto Rio das Mortes (Sangradouro e, atualmente, São Marcos) e Xingu (à época compreendendo Batovi e Simões Lopes, e hoje englobando as Terras Indígenas Marechal Rondon e Parabubure). Os Xavante Orientais, por sua vez, englobariam a região do baixo Rio das Mortes (Tls Areões e Pimentel Barbosa). Tal distinção se deve a algumas diferenças na forma de contato com a sociedade nacional, no sistema de classes de idades, na área habitada por tais grupos etc.

Na sociedade Xavante há três clãs: Poredzaono, Toptató e Öwawẽ, havendo um sistema com duas metades patrilineares exogâmicas, no qual os Poredzaono podem se casar tanto com Toptató quanto com Öwawẽ e vice- 
versa, mas estes não podem se casar entre si. A criança passará por uma série de categorias de idade. Estas, de acordo com Aracy Lopes da Silva, "dizem respeito às fases do ciclo de vida tal como reconhecidas pelos Xavante, e diferem no caso dos homens e das mulheres" (1980: 38). A criança será livre durante seus primeiros anos para conhecer sua aldeia, sendo sempre vigiada por algum parente, usualmente uma irmã mais velha ou sua avó.

A aldeia tem normalmente formato semicircular, com a abertura voltada para um curso de água corrente. As casas também são normalmente circulares, recobertas com palha de buriti, com a aparência de uma colmeia e altura aproximada de 4,5 metros. A "casa dos homens" (Hö) constitui outra importante instituição na vida social Xavante. Por volta dos 12 anos, o jovem Xavante ingressará no Hö. Saindo de lá, após passar cerca de cinco anos em relativa reclusão, o Xavante tem sua orelha furada em um complexo ritual coletivo, estando, a partir de então, apto a se casar e constituir família, se mudando para a casa da mãe de sua esposa. Vale dizer que para os Xavante é permitida a poligamia. $O$ casamento ideal acontece quando irmãs entre si casam-se com irmãos entre si, de maneira a manter a patrilinhagem após o casamento (Maybury-Lewis 1984: 135).

Deixando o $H \ddot{o}$, os rapazes deixam para trás também sua condição de wapté (adolescentes), passando a ser ritei'wa (rapazes). Além de já lhes ser permitido o casamento, os ritei'wa são vistos como o grupo mais vigoroso dentro da aldeia e no primeiro passo para se tornarem "homens maduros" (ipredu), passando a ter voz ativa nos rumos da comunidade a partir do warã - reunião que ocorre duas vezes ao dia, ao amanhecer e à noite, no centro da aldeia, funcionando como uma espécie de fórum e/ou conselho. O último passo nessa escada etária Xavante é a categoria de ĩhi (velhos). Nas últimas etapas, os principais papéis do Xavante são o de chefe de sua linhagem e/ou liderança na aldeia.

Neste intrincado contexto político, pode-se afirmar que a sociedade Xavante se caracteriza por uma emaranhada rede de relações sociais dualistas, hierarquizadas e segmentadas, constantemente oscilando entre a reciprocidade e a evitação. As situações discutidas a seguir remetem a uma estrutura dualista comum aos povos Jê do Brasil Central, marcada por oposições entre grupos de idade (jovens vs. idosos), lados da aldeia (ocidental vs. oriental); metades e/ou clãs (“meu" clã vs. "o outro" clã) etc. Segundo Barata,

é sabido que os grupos Jê [...] caracterizam-se, entre outras coisas, pela formação de unidades políticas menos inclusivas do que o próprio grupo tribal ou a aldeia, são as chamadas facções [...] Essas facções são, no mais das vezes, extremamente fluidas e de difícil detecção, tornando-se mais aparentes quase que exclusivamente nas situações em que o conflito torna-se manifesto e assumindo-se por oposição, particularmente, no que diz respeito à chefia, chegando muitas vezes a provocar cisões na aldeia (Barata 1981: 127-9).

Para os Krahò, a facção também constitui uma unidade política. Conforme Melatti, a facção é a menor e mais instável das suas unidades políticas. Para este autor, ela está

intimamente ligada ao sistema de parentesco, não podendo ser confundida, entretanto, com nenhum grupo de parentes (...) A facção, que se forma em torno de um líder, não se confunde nem mesmo com o grupo de pessoas que ele considera parentes consanguíneos. Uma facção congrega parentes consanguíneos e afins do líder, mas não todos. Espera-se que um homem tome partido de seu pai, de seu irmão, de seu tio materno; mas muitas vezes duas facções podem surgir da disputa entre dois parentes (...) Pode acontecer que uma série de reclamações, de 
acusações de feitiçaria, mantenham dois grupos de inimizade durante algum tempo; mas uma nova questão que surja dentro de um deles pode vir a produzir uma nova divisão em facções. É muito difícil identificar facções nas aldeias Krahò, a não ser quando o conflito entre elas chega a seu ápice (Melatti 1978: 74).

Para outro exemplo sobre como se verifica o faccionalismo entre os Jê, podemos recorrer ao caso Xerente. Segundo Roberto de Paula,

as facções Xerente - agrupamentos de indivíduos (consanguíneos e afins) que dão apoio a um (ou mais) líderes indígenas - vivem em constante competição, buscando o domínio político de cada uma das aldeias, como também [vivem] da comunicação e articulação com os demais agentes não índios (Paula 2005).

O faccionalismo, como se vê, é um fato que não põe em xeque a unidade do grupo por oferecer também uma saída para o conflito: a divisão da aldeia. Conforme nota Maybury-Lewis,

a facciosidade é um fato básico da vida Xavante; faz parte do esquema geral em termos do qual as pessoas orientam seu comportamento e ordenam suas categorias conceituais. As facções competem eternamente por poder e prestígio assim como pelo prêmio maior: a chefia [...] Seu pensamento a respeito das relações entre facções contém uma semelhança intrigante com o nosso próprio pensar a respeito das relações entre as grandes potências mundiais. Uma facção dominante tem à sua disposição um mecanismo de "ação inibidora maciça", que equivale a declarar guerra ao resto da comunidade e só raramente pode ser usado (Maybury-Lewis 1984: 238-66).

Como veremos, a situação em São Marcos chegou a este ponto. No entanto, a organização Jê prevê, além da divisão da aldeia, uma alternativa para auxiliar na dissolução deste tipo de situação extrema: o mediador. De acordo com Barata,

quando um conflito tende a atingir um ponto limite que possa escapar ao controle do próprio grupo, são imediatamente ativados mecanismos de ação social que possibilitem com que a situação seja contornada sem que as partes envolvidas sintam-se lesadas. Isso implica no aparecimento de um mediador que pretensamente estaria colocado em posição de neutralidade diante da questão (Barata 1981: 140-1).

Tal papel deveria ser desempenhado pelo chefe da aldeia. No caso de São Marcos, porém, notaremos que a aldeia perdera sua chefia normal. A missão que poderia mediar o conflito era uma de suas promotoras, apoiando Aniceto; enquanto a AER de Barra do Garças apoiava Orestes. Nesse sentido, é natural que os Xavante esperassem da equipe do Programa Xavante a mediação necessária. No entanto, uma vez que o Programa vinha disposto a implantar "projetos", mais que equacionar o conflito, às lideranças passou a interessar o prestígio junto àquela equipe, a fim de angariar mais recursos que os rivais. Ao grupo de Cláudio Romero não interessava a disputa, enquanto seu posicionamento era que "cabia aos Xavante encontrarem sua solução de acordo com a cultura Xavante" (comunicação pessoal). O resultado, como veremos, foi a incorporação da equipe do Programa nas disputas faccionais. 
Observa Maybury-Lewis que as sociedades dualistas como os Jê do Brasil Central

estão conscientes de que os princípios conflitantes que mantêm a harmonia do universo, a longo prazo, pode desequilibrar suas vidas individuais e sociais a curto prazo. Eles, portanto, veem seus sistemas binários como os envolvendo em um constante esforço para harmonizá-los com essas forças e para mantê-los em tensão dinâmica. Assim, as aldeias dos índios do Brasil central são elas próprias microcosmos do universo, e os rituais realizados pelos seus habitantes procuram manter suas sociedades em harmonia com o esquema cósmico das coisas (Maybury-Lewis \& Almagor 1989: 10-1; tradução minha).

Tal equilíbrio é encontrado na cosmologia - através dos mitos - e nas histórias Xavante. Além disso, pode ser visto nas incursões Xavante à Funai, funcionando como uma forma de manter aquela sociedade em harmonia segundo o esquema cósmico das coisas (usando as palavras citadas acima). O que veremos a seguir, entretanto, é que este esquema transcende as fronteiras da aldeia, abrangendo também, neste caso específico, a própria equipe do "Programa Xavante".

\section{O PALCO E SEUS ATORES}

A comunidade Xavante que atualmente habita a Terra Indígena (TI) São Marcos chegou à região em meados de 1960, quando um grupo liderado por Apoena ${ }^{3}$, vindo de Couto Magalhães e fugindo de massacres encabeçados por fazendeiros, foi recebido por uma missão salesiana cujo propósito era atrair os Bororo da região (Garfield 2001: 117). Maybury-Lewis encontrou esta comunidade na primeira metade da década de 1960, sob forte influência dos salesianos. A rotina imposta consistia em missas, aulas e troca de favores, que incluía empréstimos de maquinário e ferramentas para os Xavante trabalharem em suas roças (Maybury-Lewis 1984: 59-60).

Frente à ineficácia da Funai nas últimas quatro décadas, a influência da missão foi se consolidando e interferindo no próprio sistema de chefia da aldeia. Os Xavante passaram, então, a buscar na Funai a compensação pela falta de autonomia na aldeia, devido à presença dos missionários. Para os índios, a missão lhes era conveniente na medida em que lhes fornecia energia elétrica e trabalho. Por outro lado, a presença salesiana lhes era incômoda, uma vez que os padres normalmente impunham sua vontade, utilizando destes benefícios como moeda de troca ${ }^{4}$. Entretanto, tais imposições não se verificavam na Administração da Funai em Barra do Garças. Lá, os funcionários da Funai tratavam os índios de forma assistencialista, visando se manter em seus cargos. À época, relatavam alguns Xavante que, para se sustentar no cargo, o Administrador da Funai comprava peças para carros a preços superiores aos do mercado, dividindo a diferença entre si, o fornecedor e a liderança Xavante. Falsas ou não, tais afirmações também evidenciam a disputa faccional daquele momento, onde a comunicação pessoal, feita à maneira de confidência, era algo recorrente nesse tipo de situação. Elas também indicam que a presença do Administrador era dispensável. Em primeiro lugar, ele representava uma pessoa a mais com a qual se dividia os lucros desse tipo de negociata. Além disso, na Funai - ao contrário da missão - a chegada ao poder era viável, representando status e recursos fáceis. Se na missão os Xavante eram submetidos às vontades dos padres salesianos, a estrutura da 
Funai Ihes permitia ascender ao cargo de Administrador Regional, detendo poder, recebendo salário fixo e, dentre outras coisas, garantindo lugar de destaque em sua facção.

Assim sendo, pode-se entender o que ocorreu em seguida. Nas décadas de 1970 e 1980, durante o projeto de rizicultura entre os Xavante, as viagens dos índios a capitais como Brasília e Cuiabá se tornaram comuns. Os caciques precisavam se deslocar com intérpretes, uma vez que ainda não haviam aprendido português e tampouco os funcionários da Funai dominavam a língua Xavante. Dentre os tradutores de Apoena, encontrava-se Aniceto ${ }^{5}$, jovem que se enquadrava nos esquemas impostos pela missão. Em 1975-6, Apoena foi convencido pelos missionários a entregar parte da liderança a Aniceto, de maneira que Apoena passaria a liderar a aldeia São Marcos, enquanto Aniceto tomaria a frente nas decisões que envolvessem os brancos.

Nesse período, Orestes, filho de Apoena, estava servindo o exército, longe da aldeia. Depois de servir, Orestes foi morar em São Paulo. Segundo alguns entrevistados ${ }^{6}$, ele "não queria mais saber de aldeia, só queria morar na cidade"7. Após a morte de Apoena, aproximadamente em 1998, Orestes resolve voltar para a aldeia a fim de tomar para si o cargo de chefia deixado pelo pai.

De acordo com a tradição Xavante, ele teria o direito de assumir a liderança daquela aldeia. Isso desagradou Aniceto, irmão da mãe de Orestes. Tal fato parece estranho, visto que todos os autores estudiosos da cultura Xavante, bem como minha própria experiência, demonstram que o irmão da mãe é, normalmente, muito chegado ao sobrinho. Lopes da Silva, por exemplo, classifica a relação entre ambos como jocosa (1980: 178). A autora salienta ainda como a relação com o irmão da mãe pode ser vista, inclusive, como a de um "pai substituto" (:71). Maybury-Lewis também salienta a importância da função do tio materno, o qual dá, inclusive, o nome ao sobrinho (Maybury-Lewis 1984: 291). Assim, em vez do atrito que surgiu com o retorno de Orestes, era de se esperar uma relação de afetuosidade e respeito mútuo.

Na verdade, o que houve foi a troca de uma relação de companheirismo formal por uma de evitação formal, a partir da qual ambos evitaram o confronto direto: uma relação de distanciamento formalizado. No caso do retorno de Orestes, a relação entre Aniceto e seu sobrinho foi reconstruída, com ambos se tornando simétricos e opostos tal qual a amizade formal, como se a relação existente entre ambos consistisse na evitação, não na cooperação (Carneiro da Cunha 1978). Ela pode ter sido reconstruída a partir do lugar que ambos ocupavam na comunidade de São Marcos: a de chefes em potencial, a partir da morte de Apoena. Além disso, a relação entre cunhados (ZH e WB) é oposta à relação entre tio e sobrinho (ZS e MB). Como observa Maybury-Lewis, apesar de não haver "um contraste agudo" entre os parentes matrilineares e patrilineares, "há uma antítese marcada entre WB e ZH. Este contraste entre afins obviamente não contamina a geração seguinte para quem a oposição entre ZH e WB se transforma em uma oposição entre F e MB" (Maybury-Lewis 1984: 293). Neste caso, tal contraste parece ter se estendido a Orestes, devido à disputa faccional pela chefia formal da aldeia. Para a maior parte das lideranças de outras aldeias, Aniceto era apenas "secretário" de Apoena, não cabendo a ele - mas a seu filho - a chefia. Além disso - e isso parece ter sido decisivo neste processo - a facção de Aniceto não era a mais forte, tornando sua tomada de poder insustentável. 
Conforme explica Maybury-Lewis, "um chefe é reconhecido como tal enquanto é o cabeça de uma facção forte. Segundo o pensamento Xavante, se sua facção deixa de ser suficientemente forte e poderosa para mantê-lo naquela posição, ele perde o direito à chefia" (Maybury-Lewis 1984: 251). Nesse caso, o grupo que apoiava Aniceto deveria se retirar e fundar uma nova aldeia. No entanto, em vista das benfeitorias a que se tinha acesso devido à presença da missão salesiana, isso não se deu. Além do mais, esperar-se-ia que Orestes convocasse uma reunião no warã, centro político da aldeia, a fim de comunicar sua decisão de assumir a liderança. $O$ assunto seria, assim, tratado estritamente como problema interno à aldeia de São Marcos. Entretanto, Orestes decidiu chamar "parentes seus" - isto é, pessoas de seu clã - das outras aldeias da TI São Marcos, transformando a questão em um fato político envolvendo todas as aldeias Xavante daquela $\mathrm{Tl}$, à época com mais de três dezenas de aldeias. Dessa maneira, apesar de acuado, Aniceto permaneceu na aldeia, contando com o suporte dos missionários, enquanto Orestes era apoiado pelos caciques das outras aldeias, à exceção de duas delas. Nesse sentido, o princípio da solidariedade clânica foi utilizado por Orestes para aumentar seu poder e foi esse um dos fatores que o levou a expandir o conflito para além dos limites da aldeia São Marcos.

A disputa gerou graves conflitos, havendo mortes naquela Terra Indígena e em Barra do Garças - inclusive à luz do dia, na praça da cidade. Uma vez que Aniceto contava com o apoio dos salesianos, Orestes buscou apoio na Funai a fim de que esta lhe reconhecesse oficialmente a chefia. Nesse ínterim, assumiu o cargo de Administrador Executivo Regional da Funai em Barra do Garças um "parente" de Orestes, chamado Sávio (nome fictício), que se utilizava dessa função em benefício próprio e do seu grupo. Gerou-se, assim, descontentamento nos aliados de Aniceto, que foram progressivamente abandonados por aquele órgão.

Para se ter uma ideia da proporção que tomou o conflito na aldeia de São Marcos, o ex-presidente da Funai, Sulivan Silvestre (presidente da Funai entre agosto de 1997 e fevereiro de 1999), promoveu uma eleição naquela aldeia a fim de definir quem seria o cacique "oficial". Espantosamente, o resultado deu empate, mas, a partir daí, chamando para si a vitória, Orestes passou a assinar alguns documentos como "Presidente da Nação Xavante". Há também documentos de Aniceto e de Orestes com os carimbos de "Cacique de São Marcos Ocidental" e "Cacique de São Marcos Oriental", respectivamente.

Em fevereiro de 2001, Orestes morreu, após ter contraído hepatite (informação pessoal, fornecida pela equipe de saúde da aldeia), sendo seu lugar assumido por seu irmão, Raimundo. A morte de Orestes, ao invés de resolver o conflito, causou seu acirramento, devido a acusações de feitiçaria contra o grupo de Aniceto. Tais hostilidades extrapolaram as fronteiras da TI São Marcos, pois grupos de outras comunidades Xavante se mobilizaram para intervir no conflito, visando defender seus "parentes". Finalmente, em 2002, Aniceto foi aconselhado pelos salesianos a fundar nova aldeia na divisa da TI Merure, habitada por índios Bororo, também sob influência dos salesianos. 


\section{A FACÇÃO DE ORESTES}

A facção mobilizada por Orestes, além de ser a mais numerosa, era também mais poderosa politicamente. Exemplo disso se verificou na manhã do dia 07 de abril de 2000, no auditório do Batalhão de Polícia Militar em Barra do Garças, quando houve uma reunião entre a equipe do "Programa Xavante", a Funai e os caciques da região, para discutir as diretrizes a serem implementadas. Sávio tomou a frente da organização dessa reunião, distribuindo crachás aos caciques para que tivessem acesso ao auditório, não liberando, porém, a presença das lideranças partidárias de Aniceto. Ao contrário, foi expedida uma "Relação dos caciques que estarão presentes na reunião com o antropólogo, Sr. Cláudio Romero" - coordenador da equipe do "Programa Xavante" - na qual constavam nomes de funcionários da Funai, mas não o dos dois caciques aliados de Aniceto.

Como se vê, Orestes estava realmente em situação privilegiada. Segundo alguns de seus partidários, a função da equipe do Programa seria retirar Aniceto da aldeia São Marcos e proclamar oficialmente a chefia de Orestes. Mais que isso, deveria haver recursos financeiros suficientes para que Sávio pudesse manter as coisas sob seu controle. Outro cacique afirmou que Aniceto era mentiroso e por isso não poderia ser apoiado. Tal afirmação pode ser explicada, em parte, pela própria organização social Xavante e por seu característico faccionalismo, mencionados acima.

Em seu texto, Seth Garfield nos relata que "Aniceto tinha concedido a seus parentes cargos remunerados, como vaqueiro e motorista de trator, e excluído os parentes de Apoena" (Garfield 2001: 203; tradução minha). Os Xavante e os Jê, em geral, atribuem o prestígio da liderança não só à capacidade de aquisição de bens, mas, sobretudo à sua distribuição entre o grupo. O fato de Aniceto ser visto como "sovina", "mentiroso" e "pão-duro" por alguns dos entrevistados sugere que muito de seu poder foi sendo desgastado devido a uma suposta quebra de etiqueta Xavante. Carneiro da Cunha nos relata quanto aos Krahò - outro grupo Jê - que a generosidade constitui "a virtude cardeal Krahò", enquanto ser avaro "é um termo injurioso" (Carneiro da Cunha 1978: 44; ênfase no original).

No entanto, passado algum tempo, o grupo de Orestes percebeu que a equipe do Programa não foi a Barra do Garças para oficializá-lo na chefia, tampouco dispunha dos recursos financeiros necessários à manutenção de Sávio à frente da AER. O Programa deixava de lhe ser conveniente e esta situação iniciou uma sucessão de boatos e viagens à Brasília em táxis fretados por Sávio. Os boatos eram de toda espécie, desde os que diziam que a equipe estava apoiando Aniceto às escondidas, até os que colocavam membros da equipe como administradores em potencial, no lugar de Sávio. No que se refere aos boatos, até hoje os índios da facção de Orestes garantem que foram espalhados pelo grupo de Aniceto, visando desacreditar o Programa. Quanto às viagens, eram feitas às expensas da AER/Barra do Garças a fim de pressionar a Presidência do órgão a retirar a equipe, visto que as auditorias feitas demonstravam claramente superfaturamento nas compras e desvio de recursos. Em resumo, a inserção da equipe do Programa, nesse contexto, era percebida por Orestes como uma ameaça à manutenção de seu poder na Funai. 


\section{A FACÇÃO DE ANICETO}

Aniceto, assim como Orestes, esperava que o Programa legitimasse seu poder. Mais do que isso, a presença da equipe garantia, àqueles que o apoiavam, a assistência necessária. Os partidários de Aniceto vinham sendo paulatinamente ignorados pela AER e por Sávio, que mantinha no prédio da Administração uma dezena de "seguranças": índios de sua facção armados a fim de garantir que aliados de Aniceto não aparecessem. Nesse sentido, a ida da equipe, investida de algum poder, funcionou contrabalançando a autoridade de Sávio e Orestes. Há pelo menos dois exemplos disso: durante a reunião no quartel, dia 07 de abril de 2000, Aniceto se fez presente e discursou em português para que se fizesse entender - ao contrário das outras lideranças, que falavam em Xavante -, criticando a corrupção na AER de Barra do Garças. Uma vez que a reunião se deu em um Batalhão da Polícia Militar, sua integridade física foi garantida. Outro exemplo foi no dia seguinte, em pleno prédio da AER, quando Jeremias - funcionário da Funai em Brasília e ex-vereador em Barra do Garças - desferiu acusações semelhantes, afirmando ter provas - que não chegou a apresentar.

Interessante notar como o grupo de Aniceto se esforçava por se demonstrar "superior" aos seus rivais e afirmar que era tão apto à liderança quanto Orestes que vivera por anos entre os brancos. Jeremias, por exemplo, respondeu a Cláudio Romero durante a reunião de 06 de abril de 2000: "estamos aqui, conversando democraticamente, como gente civilizada. É boa a forma antropológica que você expôs [...] Eu e outros companheiros civilizados...". Tais observações também eram feitas a fim de deixar claro que o grupo de Aniceto era mais pacífico que o de Orestes. Este frequentemente vinha a Brasília "fechar a Funai" - menção clara às frequentes ocupações da sede da Funai na capital federal, analisadas em Fernandes (2005). Tal superioridade deveria ser, aos seus olhos, mais um motivo pelo qual Aniceto e seu grupo deveriam ser oficialmente anunciados como lideranças em São Marcos.

Isso tudo não quer dizer que Aniceto fosse favorável à presença do Programa em Barra do Garças. Até certo ponto ele, como Orestes, não teria o que perder, mas à medida que o tempo passava, Aniceto foi percebendo que a presença de Cláudio Romero e sua equipe em nada alteraria seu status, conforme previsto. Gradativamente, Aniceto foi deixando de visitar a equipe do Programa Xavante. Paralelamente, ele e seus aliados iniciaram um lobby visando à abertura de uma AER em General Carneiro/MT, que visasse atender a ele e seus correligionários. Tal pleito, no entanto, não obteve êxito por uma série de motivos: falta de recursos; a crise que se instaurou na Funai em Brasília após a demissão de Carlos Marés durante as já mencionadas "festividades" dos 500 anos do descobrimento; e outras propostas de lideranças Xavante de outras Tls (Parabubure, Areões e Culuene) que se sentiam prejudicadas em disputas faccionais.

Antes de passar à análise da situação aqui exposta, cabe justificar ao leitor o porquê de este artigo haver esperado uma década para ser escrito. Parte dele compôs meus primeiros trabalhos sobre a cosmologia do contato entre os 
Xavante e posteriormente, minha própria dissertação de mestrado (Fernandes 2005) sobre as ocupações xavante na sede da Funai em Brasília, levando em consideração sua organização social e sua cosmologia. Contudo, à luz de esforços intelectuais mais recentes (sintetizados em parte em Fernandes 2010) e, após mais de uma década de pesquisas entre os Xavante, percebo que há ainda alguns aspectos importantes a serem destacados na situação aqui descrita.

Em primeiro lugar, cabe dizer que o foco das políticas xavante vão se deslocando na situação aqui analisada, gradativamente, para o exterior da aldeia. Isso implicaria em uma espécie de "contaminação waraduzu" nas políticas Xavante? Penso justamente o contrário. É importante entendermos que o lugar da coletividade por excelência entre os Xavante é o warã, o conselho da aldeia que se reúne todos os dias em seu centro, buscando tomar as decisões mais importantes. O que caracteriza o warã é, dentre outras coisas ${ }^{8}: 1$ ) ser um lugar masculino; 2) a oralidade - através de discursos cerimoniais ou não; 3) a participação de diferentes atores, se constituindo no fórum deliberativo por excelência.

Conforme observa Graham, quanto às práticas discursivas do warã:

As práticas discursivas de reuniões do warã física e acusticamente obscurecem o faccionalismo que sempre ameaça destruir a comunidade; as práticas discursivas no warã, assim, continuamente reproduzem e reforçam as relações igualitárias entre os participantes maduros do sexo masculino, mantendo a comunidade unida. No entanto, simultaneamente, os limites institucionalizados sobre o acesso a formas discursivas empregadas no discurso político recriam relações de dominação em termos de idade e sexo (Graham 1993: 718, tradução minha).

Já ouvi de alguns Xavante que "Xavante não existe sozinho", se referindo ao aspecto de complementaridade dos diferentes clãs, grupos de idade, classes de idade etc. Isso chama atenção para o próprio conceito de "facções", que devemos compreender como grupos políticos em disputa entre si. Ora, a facção Jê, entendida nos termos mencionados até aqui, somente faz sentido se tomada por complementaridade, como chamou a atenção Carneiro da Cunha em relação ao pensamento Krahò (1978: 145). Nesse caso, "disputa" resolve apenas parte do problema enquanto tais grupos estiverem competindo entre si. Entretanto, tais grupos somente podem ser entendidos quando vistos enquanto existindo em oposição um ao outro. Poderíamos afirmar que a disputa é a característica mais acentuada e comum da relação interfacções, enquanto da relação interétnica é o conflito, mas tanto uma quanto outra coisa ocorre em ambos os tipos de relações.

É interessante notar como essas hostilidades dão suporte à sociedade Xavante: oposição entre os diferentes grupos de idade; entre amizade formal e evitação; entre metades; entre família da esposa e marido; e, finalmente, entre reciprocidade positiva e negativa. Nesse sentido, é possível dizer que o tipo de fenômeno Xavante que aqui focalizo evidencia esse duplo sentido das relações: a reciprocidade "positiva", a partir da qual as pessoas se unem por laços "afetivos"; e a reciprocidade "negativa", onde as pessoas também se unem, mas por laços de rivalidade. Um grupo, ao se afirmar em relação a outro, aumenta suas possibilidades de reprodução como tal, reforçando sua identidade interna e, com isso, aumentando sua coesão e a coesão do seu oposto, gerando equilíbrio. 
No caso da disputa faccional entre os grupos de Aniceto e de Orestes poderíamos dizer que foi essa a situação atingida. O grupo de Orestes se manteve no comando da Administração da Funai em Barra do Garças, enquanto o grupo de Aniceto garantiu apoio da Funai em Brasília para instalar sua nova aldeia e para a criação (e chefia) da unidade da Funai criada em General Carneiro. Não se pode dizer que alguma dessas facções tenha sido preterida na distribuição de bens e/ou cargos e, de certa maneira, houve uma cooperação entre os dois grupos ainda que involuntária. Os ganhos de um geram a compensação - e, consequentemente, outros ganhos - para o grupo oposto, produzindo relativo equilíbrio.

Esse equilíbrio garante a existência de uma facção enquanto tal, uma vez que, para um chefe de aldeia ou para o cabeça de uma facção, derrota é voltar para a aldeia de mãos vazias, sem recursos que possam ser distribuídos aos membros de seu grupo. Outra falha grave geradora inclusive de cisões em aldeias é quando a liderança não distribui adequadamente os bens obtidos, beneficiando mais uns que outros. Quebrar-se-ia, assim, o ciclo de reciprocidade que caracteriza a chefia enquanto atributo básico da liderança (Lévi-Strauss 1944: 29).

Contudo, há ainda outro aspecto para o qual se deve chamar atenção neste trabalho, que diz respeito ao contexto aqui descrito à luz das relações interétnicas. Em resumo, pode-se afirmar que todos parecem se subsumir à dinâmica faccional, inclusive os não índios. Uma visada nas minhas anotações de campo da época, com a perspectiva que o tempo e a experiência nos emprestam, deixa isso claro no discurso dos funcionários da Funai que compunham o Programa. A ver:

Dia cinco de abril de 2000, quarta-feira, 19 horas. Ao grupo de Orestes é dito que o papel do Programa é "discutir como e porque os Xavante estão brigando entre si", buscando elaborar "projetos para toda a família, não para uma ou outra família". Após os Xavante saírem, um dos coordenadores diz a equipe: "eles querem é nos por na briga deles". O objetivo do trabalho seria, pois, "unir os Xavante, ajudando a mudar a situação". No dia seguinte, pela manhã, é dito pelos Xavante em reunião, que "hoje em dia é preciso que o Projeto aborde a comunidade como um todo, apesar das divisões. Recurso é de todos, é da união, da comunidade". Á tarde somos procurados por um grupo ligado a Aniceto, que pediu que o grupo de Orestes fosse retirado da aldeia. Dia oito de abril, à noite: íamos à aldeia de São Marcos, mas como tanto um quanto outro grupo veio até o hotel nos avisar que o opositor estaria preparando tocaias na mata para agredir a equipe do Projeto, optamos por ir até a Terra Indígena Sangradouro e lá ficar até o dia quatorze de abril.

No início de maio, os Xavante do grupo de Orestes passaram a viajar sistematicamente à Brasília, por entender que a equipe do Programa teria por objetivo retirar-lhe a influência sobre a Administração Regional. À época, os dados do Programa deram conta de que haveria, na área dos Xavante, cerca de 11.000 índios distribuídos em 160 aldeias, com 170 carros nas mãos dos indígenas, além de inúmeras denúncias de irregularidades (incluindo aí extorsão e chantagem de comerciantes, superfaturamento de preços e direcionamento dos recursos da Funai local para grupos políticos específicos). Compreendo, a esta altura, que em um primeiro momento a disputa era pela equipe do Programa Xavante, enquanto ela representasse um aporte de recursos - simbólicos, inclusive a serem incorporados pelas redes de troca inerentes às facções e grupos políticos. Adiante, contudo, a equipe passou a ser vista como um estorvo por ambos os grupos, justamente por colocar em xeque a autoridade do 
grupo encabeçado por Orestes, bem como se mostrar inoperante em um eventual reconhecimento da liderança exercida por Aniceto. A alternativa escolhida por ambas as facções, quanto à equipe do Programa, acabou sendo a mesma que adotaram para mediar as relações que existiam entre elas, ou seja: aguardar o desmantelamento da coalizão faccional potencialmente hegemônica, isto é, a equipe da Funai de Brasília.

Éramos, pois, mais uma entre as facções operando nesse complexo tabuleiro, sem que isso representasse qualquer contradição às regras do jogo. Remeto aqui, por exemplo, ao mito de fundação da Funai pelos Xavante, que me foi contado por uma das lideranças de São Marcos, em 2002:

... é por isso [que] outro índio [os não Xavantes] não vem aqui Brasília, porque são atrasado, né? Ainda não tem desenvolvido, não tem capacidade, não tem muito experiência de estudante... (...) ["antigamente"] os Xavante mantém contato com civilização, já entra SPI, já tá procurando a civilizaçãa, conhecer, cada vez mais do homem. Índio quer conhecer cada vez mais, cada vez mais o homem [branco]... Índio [Xavante] abriu projeto em defesa de todas as nações indígenas brasileiras. Xavante. Xavante tá defendendo tudo, nações indígenas brasileiras, né? Então, Xavante fundou SPI, que hoje é Funai. Agora vem outro índio... "ah, já tem Funai, agora já tem subordinado, já tem cuidar o índio do Brasil, é a Funai, então vamos também", então cada vez mais aparece, vem aparecendo, vai aparecendo aí... Mas o primeiro que fundou, que fundou, foi o índio Xavante, que fundou isso aí, é... Do tempo de general Rondon.

Dessa forma, a manipulação, simbólica e/ou material dos recursos provenientes da Funai é, pode-se dizer, uma maneira de manter o esquema cósmico das coisas, posto que a Fundação Nacional do Índio era entendida, por eles, como sendo dos Xavante!

Escrevi alhures (Fernandes 2010) justamente como esse caráter - da incorporação do exterior - faz parte da cosmologia Jê-Xavante, sendo a gradativa inclusão da equipe do Programa neste esquema uma demonstração do poder de agência daqueles índios no plano sócio-cosmológico e das relações no plano interétnico, bem como interfaccional. Concordo com Graham (1995), no sentido de que tais ações, empregadas pelos Xavante e aqui narradas, são um meio pelo qual esses índios reafirmam, dentre outras coisas, aspectos essenciais de sua cultura, um senso de continuidade e de resistência - uma vez que "experimentam mudanças dramáticas em suas formas tradicionais de vida" (1995: 06). Em vez de mostrar que os Xavante estariam "mal-acostumados" e que tais eventos demonstrariam uma subserviência ao clientelismo imposto pela Funai, os Xavante estariam reforçando aspectos de seu próprio sistema social e político, bem como cosmológico.

Estevão Rafael Fernandes é Mestre em Antropologia Social pela Universidade de Brasília. Atualmente cursa Doutorado no Centro de Pesquisa e Pós-Graduação sobre as Américas da Universidade de Brasília (Ceppac/UnB) e é Professor do Departamento de Ciências Sociais da Universidade Federal de Rondônia 


\section{NOTAS}

1 Agradeço imensamente pelos valiosos comentários aos pareceristas anônimos da Revista Campos (UFPR), bem como aos professores Roberto Cardoso de Oliveira (in memoriam), Julio Cezar Melatti e Henyo Trindade Barretto Filho, a quem submeti minhas primeiras anotações sobre o assunto, muitas das quais constam neste texto, à época de meu mestrado.

2 Para maiores detalhes sobre esse processo, ver Toral (1986).

3 Este Apoena não é o famoso líder Xavante, que liderava o grupo que fez o primeiro contato pacífico com Francisco Meirelles, mas outro, proveniente de Couto Magalhães, região próxima a Xavantina.

4 Um exemplo disso: nos dias em que a missa na igreja de São Marcos conta com poucos índios, a missão cortava, como represália, o fornecimento de energia elétrica.

5 Para referências a Aniceto, ver Maybury-Lewis (1990: 411- 417) e Garfield (2001:174; 203-4; 212).

6 A maior parte dos entrevistados solicitou que não lhes identificasse, a fim de não se comprometerem. Por uma questão de ética e por crer que isso não prejudique significativamente este trabalho, farei conforme me foi pedido.

7 Importante ao leitor situar essa afirmação, dita por um dos membros da facção oposta a Orestes. Entre os Xavante é frequente a saída dos jovens de suas aldeias para aprenderem sobre a forma de vida dos waradzu, de modo que a acusação de que Orestes seria menos índio por conta de sua saída faz sentido, sobretudo, dentro do contexto de conflito narrado aqui.

8 Cf. Maybury-Lewis (1984:193-198). 


\section{REFERÊNCIAS BIBLIOGRÁFICAS}

BARATA, Maria Helena. 1981. Os Pukopyê e os Kupen: Análise de um Drama. Dissertação de Mestrado. Brasília: Programa de Pós-Graduação em Antropologia Social, Universidade de Brasília.

BRASIL, Presidência da Funai. 2000. Portaria 047, de 03 de fevereiro de 2000.

BRASIL. 2000. Instrução Técnica Executiva 064, de 23 de março de 2000.

CARNEIRO DA CUNHA, Manuela. 1978. Os Mortos e os outros. S. Paulo: Hucitec.

FERNANDES, Estevão Rafael. 2005. Entre cosmologias, estratégias e performances: incursões Xavante à Funai. Dissertação (Mestrado). Dissertação de Mestrado. Brasília: Programa de Pós-Graduação em Antropologia Social, Universidade de Brasília.

2010. “Do Tsihuri ao Waradzu: o que as ideologias xavante de concepção, substância e formação da pessoa nos dizem sobre o estatuto ontológico do outro?". Horizontes antropológicos 16(34): 453-477.

GARFIELD, Seth. 2001. Indigenous struggle at the heart of Brazil: State policy, Frontier expansion, and the Xavante indians, 1937-1988. Durham: Duke University Press.

GRAHAM, Laura R. 1993. “A Public Sphere in Amazonia? The depersonalized collaborative construction of the discourse in Xavante". American Ethnologist 20(4): 717-41.

1995. Performing Dreams: Discourse of immortality among the xavante of Central Brazil. Austin: University of Texas Press.

LEVI-STRAUSS, Claude. 1944. “The Social and Psychological Aspect of Chieftainship in a Primitive Tribe: the Nambikuara of Northwestern Mato Grosso" Transactions of The New York Academy of Sciences, Ser. II, 7(01): 16-32.

LOPES DA SILVA, Aracy. 1980. Nomes e Amigos: da prática Xavante a uma reflexão sobre os Jê. Tese de Doutorado. São Paulo: Programa de Pós-Graduação em Antropologia Social, Universidade de São Paulo.

MAYBURY-LEWIS, David. 1984. A sociedade Xavante. Rio de Janeiro: Francisco Alves.

\& ALMAGOR, Uri (eds.). 1989. The Attraction of opposites - Thought and Society in the dualistic mode. Ann Arbor: Un. Of Michigan Press.

MELATTI, Julio Cezar. 1967. Índios e Criadores - A situação dos Krahó na área pastoril do Tocantins. Monografias do ICS, Vol. 3. Rio de Janeiro: UFRJ.

1972. Messianismo Krahó. São Paulo: Herder. Disponível em ‘http://www.geocities.com/juliomelatti/livro72/ mess.htm. Acesso: Janeiro de 2005.

1978. Ritos de uma tribo timbira. S. Paulo: Ática. 1978.

MENEZES, Cláudia. 1985. Missionários e índios em Mato Grosso: os Xavantes da Reserva de São Marcos. Tese de Doutorado. São Paulo: Programa de Pós-Graduação em Antropologia Social, Universidade de São Paulo. 
1999. "Missionários e guerreiros: o apostolado salesiano entre os Xavante". In Robin Wright (Org.) Transformando os Deuses: os múltiplos sentidos da conversão entre os povos indígenas no Brasil. Campinas: Unicamp.

PAULA, Luís Roberto de. 2005. “Verbete Xerente” In Enciclopédia dos Povos Indígenas/ISA. Disponível em ıhttp://www. socioambiental.org/pib/epi/xerente/xerente.shtm). Acesso: Janeiro de 2005.

SECRETARIA ESPECIAL DE SAÚDE INDÍGENA (SESAI). 2013. População Indígena DSEI Xavante. Portal eletrônico da Secretaria Especial de Saúde Indígena. Disponível em < http://portal.saude.gov.br/portal/arquivos/pdf/pop_dsei_ xavante_sesai_2011.pdf>. Acesso: Maio de 2013

TORAL, André A. 1986. “Xavantaço ou Funailaço?" In CEDI. Aconteceu Especial 17 - Povos Indígenas no Brasil - 85/86. São Paulo: Centro Ecumênico de Documentação e Informação. 
“Eles querem é nos por na briga deles!": Um estudo de caso sobre faccionalismo e estratégias entre os índios Xavante (MT)

\section{RESUMO}

A partir de um estudo de caso de uma situação de conflito ocorrida no ano 2000 na aldeia xavante de São Marcos (Terra Indígena São Marcos, Mato Grosso), envolvendo diferentes facções, missionários salesianos e Funai, este artigo busca revisitar o tema do faccionalismo entre Xavante. Os dados etnográficos, após apresentados e analisados à luz da literatura disponível sobre os Xavante, são comparados com os de outros povos Jê, indicando que outras perspectivas de análise são possíveis, ainda que se trate de uma temática clássica da etnologia brasileira.

PALAVRAS-CHAVE: Índios Xavante; Povos Jê; Etnologia Sul-Americana; Organização Social; Faccionalismo.

"They want us in their fight": A case study of factionalism and strategies among the Xavante (MT)

\section{ABSTRACT}

Starting from a case study of a conflict occurred in 2000 in the Shavante village of São Marcos (Reserve São Marcos, Mato Grosso, Brazil) involving different indigenous factions, Salesian missionaries and the National Indian Bureau (Funai), this article seeks to revisit the issue of factionalism among the Shavante in their relationship with a Funai team recently arrived to their area. First, the ethnographic data are presented and analyzed in the perspective of the available literature about the Shavante Indians. Then, the data are compared with data obtained in other Ge groups, indicating that different analytical perspectives are possible, although it is a classic theme of Brazilian ethnology.

KEY WORDS: Shavante Indians; Ge Speaking Indians; South American Ethnology; Social Organization; Factionalism. 